\title{
Suggestions for authors of medical articles
}

\section{Sugestões para os autores de artigos médicos}

\author{
Péricles Maranhão-Filho'
}

\begin{abstract}
This manuscript is directed to those interested in writing medical articles. The author advises the use of certain conventions giving specific suggestions in homogenize the language of manuscripts whose purpose is their publication in specialized journals.
\end{abstract}

Keywords: manuscript, medical; medical journals; authorship and co-authorship in scientific publications.

\section{RESUMO}

Este manuscrito é dirigido aos interessados em escrever artigos médicos. O autor aconselha utilizar determinadas conveniências - sugestões pontuais - afim de homogeneizar a linguagem dos seus escritos cuja finalidade seja a publicação em periódicos especializados.

Palavras-chave: manuscritos médicos; periódicos médicos; autoria e coautoria na publicação científica.

Medical journals comprise several sections - original articles, case presentations, reviews, opinions, historical accounts, images, etc. Each one of these sections has its own requirements for formatting. Traditionally, editors, reviewers, and authors have expressed concerns about the form, content and ethical commitment of manuscripts sent for publication ${ }^{1,2,3,4}$.

According to teacher, doctor and writer Wilson L. Sanvito ${ }^{5}$, and paraphrasing Graciliano Ramos, on the preparation of a medical article: "It should be written the way the washerwomen from Alagoas* do their work. They start with a quick wash and wet the dirty cloth in the pond or stream edge. Then they twist the cloth, wet it and twist it again. After this, they soap it and twist it once or twice more. Then, they rinse it, and wet it once again by throwing water on it with theirs hands. They hit the cloth on a concrete slab or on a clean stone. They twist it again and again, wringing it so it does not drip a drop from the fabric. Just after this is all done, they hang the clothing on a rope or clothesline to dry". And Sanvito concludes, "One who gets to write should do the same thing".

With this reasoning, and without major pretensions, we consider the opinions of some experts on the subject, and list advice that can guide authors in targeting their articles for publication in medical journals.

*Alagoas is one of the 27 states of Brazil, situated in the eastern part of the northeast region (Note from the author).

\section{SUGGESTIONS}

1) Carefully read the "Information for authors" and keep yourself well within the limits suggested by the magazine. Incorrect styles annoy the reviewers and editors, as well as obscuring the scientific value of the manuscript. Do not digress. Write simply and concisely. Be sure that your words express your ideas and effectively carry your message ${ }^{2}$. Remember: "... anything that is worth telling everyone, is usually said twice in a better way with half the number of words...";

2) Only send manuscripts containing something new, such as new information or a useful message like a contribution to a subject already known ${ }^{1}$;

3) The title of the article should be concise. Creativity and originality in choosing the right words helps attract the reader's attention. The summary should be objective, consistent and generally should not exceed 150 words ${ }^{3}$. Do not use abbreviations and avoid statistical data. Use words instead of numbers;

4) Review your writing carefully and eliminate spelling, punctuation and grammatical errors. When entering the final form (especially if someone else typed the manuscript for you), be sure to review it again. A useful piece of advice: once ready, do not read it for a week, and then review it again;

5) Be accurate when referring to numerical data, whether yours or by other authors. It is not relevant to put random values (especially of decimals) found in the results or discussion sections, in the summary;

${ }^{1}$ Universidade Federal do Rio de Janeiro, Hospital Universitário Clementino Fraga Filho, Departamento de Neurologia, Rio de Janeiro, RJ, Brazil. Correspondence: Péricles Maranhão-Filho;Av. Prefeito Dulcídio Cardoso, 1680/1802; 22620-311Rio de Janeiro RJ, Brasil; E-mail: pmaranhaofilho@gmail.com Conflict of interest: There is no conflict of interest to declare.

Received 29 October 2016; Accepted 08 November 2016. 
6) Make sure you are using good sources of information. Keep in mind that: "You will find it very good practice always to verify your references, Sir!" - Martin Joseph Roth (1755-1854) ${ }^{6}$. Correctly write the names of the authors mentioned in the text (check these letter by letter). Do not copy critical expressions written by others, conveying them as if they were yours; a simple change in the sentence construction does not relieve the responsibility of indicating who the real author is; use quotation marks when transcribing whole parts by other authors ${ }^{1}$;

7) Scrupulously check the accuracy of your references. Incorrect citations are a disservice to the reader. Use only strictly necessary references. Always give preference to original sources;

8) Do not think that publishers are required to rewrite incorrect manuscripts; this is a responsibility of the authors. Those who have difficulty in writing scientific texts in english should ask for help from a colleague who is competent in that language, or should pay for help (professional) ${ }^{2}$. It is mandatory to submit the work for the most experienced person's critique, when the author is an integral part of an Institution or Service, whose name will be linked to the publication ${ }^{1}$;

9) Structure your article to answer four main issues ${ }^{2,3}$ :

a) What did you set up to do and why? INTRODUCTION

b) How did you do it? METHOD

c) What did you get? RESULTS

d) Compare what you found with the literature; DISCUSSION;

10) It is easy to confuse fact with opinion. Separate the results from the discussion, but keep the discussion clearly reasoned, concise and focused on the implications of the results;

11) Avoid repetitions ${ }^{2}$.

a) Do not repeat the SUMMARY in the INTRODUCTION or in the DISCUSSION.

b) Do not reveal your RESULTS in the INTRODUCTION.

c) Do not repeat the INTRODUCTION in the DISCUSSION.

In the text, do not repeat the legends of the images, tables or table contents (as average values and standard deviation). If you can summarize the information in one sentence, then a table or graph is not necessary ${ }^{7}$;

12) A paragraph full of numbers makes reading unattractive. Use words to summarize the meaning of the tables, keeping the message short and clear. If the reader needs more precise data, he should refer to the table. Do not add unnecessary tables with few features, or just to list words. Rather, give preference to flowing text in the body of the article. It takes up less space ${ }^{2}$. Only reproduce illustrations of other people's work after obtaining the consent of the author and the editor of the magazine that published them originally ${ }^{1}$;

13) Always use the active voice in the Summary, Introduction and Discussion. The passive voice is boring; it suggests a lack of conviction, requires more words, extends the reading time and can be ambiguous. The active voice is short, clear, strong and more emphatic. The passive voice is appropriate for use in Results and Methods ${ }^{3}$;
14) Avoid phrase constructions that force the reader to stop and reread the sentence. When you find yourself using "respectively", you are in trouble. For example: the average values for men and women are $\mathrm{X}$ and $\mathrm{Y}$, respectively. Replace it with: the average value for men was $X$, and for women it was Y. This is a direct way and allows the reader to continue reading ${ }^{2}$;

15) The skin color and ethnic origin of the patient are usually superfluous and should appear in case reports only if relevant, and then only if it is mentioned in the discussion later. For color - the criteria approved by the Brazilian Institute of Geography and Statistics (IBGE) is for the use of Black and White instead of Dark and Caucasian²;

16) Do not use the term "in man". "Humans" is a suitable alternative and can be used as an adjective or noun, without evoking controversy;

17) References should be limited to those of real importance ${ }^{4}$. To insert references in an incorrect style suggests that the article was rejected by another journal, and it was not changed for resubmission;

18) It is good form to thank - in footnotes or in the end of the work - any third-party help received, such as material and moral support, constructive criticism, suggestions for writing and bibliography compilation;

19) Currently, the submission of articles is done by using online systems.

Some of these systems request the author to suggest names of potential reviewers. It is good form to avoid the appointment of people from your department.

\section{FINAL SUGGESTIONS}

1) Many publishers do not like the use of "and/or". The meaning is often sufficient with "or". If it is important, use "or both" at the end of the sentence. ("Subarachnoid hemorrhage may cause headache, stiff neck, or both");

2) "The cause(s) of bad writing are various". This is a poor construction for reading. Use singular or plural but not both;

3) The expressions "incidence" and "prevalence" need a population denominator. Without the population value, the correct terms, all synonyms, are: "relative frequency", "frequency", "rate" or "percentage". "Mortality rate" also requires a population denominator and time period; deaths of a number of patients can provide a "case fatality rate" but not a "mortality rate";

4) The abbreviation "CNS" can only be used when referring to the brain or spinal cord. It is not synonymous with "brain" or "cerebral";

5) The term "deficit" should be used only to describe a "sign" but not neurological symptoms. The specific nature of the "deficit" needs to be obvious according to the above information; 
6) The construction, "he/she" should be avoided by placing the subject in the plural form. For example, instead of using: "The doctor can perform a lumbar puncture if he/she suspects an infectious etiology", use: "Doctors can perform... whenever they suspect ... ";

7) Some expressions and phrases that should be eliminated: "previous history" (all history is prior) and "careful examination and history" (we are always careful). Other expressions to avoid are $^{8}$ :

a) It is shown that

b) It can be noticed that

c) It has to be mentioned that

d) It should however be noted that e) It is clear that; regarding this fact that

f) It is given by the fact

g) It takes into account the fact that.

\section{CONCLUSION}

A medical article is medical but it is also an article. Therefore, it needs to follow rules and certain basic technical criteria to turn it into a pleasant and intelligible read. We believe that the application of some simple features can make it a better article subject to acceptance by the journal.

\section{References}

1. Lange O. Sugestões para os que desejam publicar trabalhos. Arq Neuropsiquiatr 1975;33:297-300.

2. Daroff RB, Rowland LP, Rossi A, Stevens-Ross L. Suggestions to authors. Neurology. 1990;40:1907-8.

3. Daroff RB, Rowland LP, Scism C. Suggestions to authors. Neurology. 1988;38:1657-8.

4. DeJong RN. To our readers and authors. Neurology. 1952;2:457-8.

5. Sanvito WL. O fascínio das neurociências: o conhecimento, rumo ao prazer. Migrâneas Cefaléias. 2006;9(1):27-31.
6. Wartenberg R. Lasègue sign and Kernig sign; historical notes. AMA Arch Neurol Psychiatry. 1951;66(1):58-60.

7. Columbia University. Biological Sciences. Writing a scientific research article. New York, 2004 [cited: 2016 Oct 8]. Available from: http://www.columbia.edu/cu/biology/ug/research/paper.html

8. Patience GS, Boffito DC, Patience PA. Writing a scientific paper: from clutter to clarity. 2014 [cited: 2016 Oct 8]. Available from: https://www. publishingcampus.elsevier.com/websites/elsevier_publishingcampus/ files/Guides/2014-01-15-Manuscript-preparation.pdf 